\title{
Characterization of selected properties of WC-WB-Co and WC-FeCrAl coatings applied by HVOF technology
}

\author{
Brezinová J., Guzanová A., Draganovská D., Brezina J. \\ Department of Mechanical Technology and Materials, Technical University of Košice \\ E-mail: janette.brezinova@tuke.sk
}

The paper presents results of the research focused on the characterization of two types of coatings - WC-FeCrAl and $W C-W B-C o$. The properties of the $W C-F e C r A l$ coating (Co and $\mathrm{Ni}$ free) were compared against the $W C-W B-C o$ coating to see if it could be used as an environmentally more suitable substitute for conventional Co and Ni containing powders. The coatings were applied by HVOF technology. The influence of thermal cyclic stress on the hardness, adhesion of coatings and their corrosion resistance was determined. A change in the phase composition of coatings after thermal cyclic loading was also determined.

\section{INTRODUCTION}

The thermally sprayed coatings, due to the wide range of applied materials, are used in almost all fields of industry. The purpose of application of coatings produced by thermal spraying is to modify or restore functional surfaces with specific properties on machine parts while reducing production and operating costs. This technology can be used in the field of primary production, but also in repairs and renovations.

Thermally sprayed coatings are often used for their increased resistance to corrosion and wear [1-8]. The positive properties of coatings applied by HVOF (High Velocity Oxygen Fuel) technology include low porosity and good adhesion. The most commonly used materials for HVOF spraying are cermets, most often based on tungsten carbide and chromium carbide. Due to the undesirable effects of cobalt and nickel on human health, the development of new "green carbide" powders has begun to improve health and safety at work. Green carbides powder WC-FeCrAl consists of WC particle in Ni- and Co-free metallic binder - FeCrAl. Green means, it is eco-friendly powder. Cobalt is a hazardous metal, toxic to water sources. Source of cobalt can be found in wastewater from metallurgical industry and electroplating plants. Risks in the operation of spraying: inhalation of the WC particles in powder or gaseous form, dermal contact when handling powder, spraying equipment or sprayed parts.
Nickel is a metal that is released into the air in the production of metal and its alloys. It cannot be digested by the digestive tract. Nickel causes allergic reactions to sensitive people, lung damage, it is a proven carcinogen. In spraying operation, despite safety precautions and protective equipment, inhalation and dermal contact may occur. Therefore, medical examinations are mandatory twice a year - hearing, liver, lungs, blood tests. Great attention is also paid to handling the powder. Powder life in plant forms a closed cycle, the powders are sprayed in a closed room, the air is filtered, the captured powder is stored in a separate container and transported to a hazardous waste dump. Nickel must not get into the air, water or soil.

Green carbides powder (WC-FeCrAl) can serve as ecologically acceptable replacement for $\mathrm{WC}-\mathrm{Co}$ or WC-Ni coatings [1-6]. This coating meets all the requirements placed on tungsten carbide powders and at the same time reduces the risks to the environment and human health.

The paper deals with the characterization of selected properties of coatings sprayed by HVOF technology.

\section{MATERIALS AND METHODS}

Experimental work was focused on determining the quality of two types of coatings applied by HVOF technology: WC-FeCrAl and WC-WB-Co. The WC-FeCrAl $(-45 /+15 \mu \mathrm{m}) 85 / 15$ powder was specially developed for HVOF applications. It is environmentally friendly without the emission of cobalt and nickel. It belongs to the group of so-called "green carbides" powders. WC-WB-Co powder $(-45 /+15 \mu \mathrm{m}) 60 / 30 / 10$ is applied with HVOF technology, the base of this coating is tungsten carbide and boron carbide. The chemical composition of the evaluated coatings is shown in Table 1.

The powders were deposited by HVOF technology, spraying device PRAXAIR TAFA JP 5000 with HP/HVOF system and Powder Feeder 1264 was used. 
Tab. 1. Chemical composition of feedstock powders [wt. \%]

\begin{tabular}{|l|c|c|c|c|c|c|c|}
\hline & C & Fe & Cr & Al & B & Co & W \\
\hline WC-FeCrAl & $5.4-5.9$ & $10-12$ & $2.5-3.8$ & $0.6-1.2$ & - & - & bal. \\
\hline WC-WB-Co & $3.5-4.0$ & - & - & - & $1.5-2.5$ & $9-11$ & bal. \\
\hline
\end{tabular}

Spraying parameters: nozzle diameter $-25.4 \mathrm{~mm}$, Kerosine flow rate $6.0 \mathrm{~g} \mathrm{~h}^{-1}\left(22.7 \mathrm{l} \mathrm{h}^{-1}\right)$, oxygen flow rate $8001 \mathrm{~min}^{-1}$, nozzle-substrate distance $380 \mathrm{~mm}$, particle speed $800 \mathrm{~m} \mathrm{~s}^{-1}$, oxide content approx. $1 \%$, spraying power $5 \mathrm{~kg} \mathrm{~h}^{-1}$.

The powders were applied to the AISI $316 \mathrm{~L}$ steel. It is an austenitic, stainless, acid-resistant steel with a tendency to pitting corrosion in solutions containing chlorine. This steel is used in chemical industry for the manufacture of engineering parts, devices and apparatus working in aggressive corrosion environment. The shape of the test bodies was cylindrical with a diameter of $25 \mathrm{~mm}$, the coatings were applied to the cylinder head. Prior to application of the coatings, the base material was cleaned and roughened by abrasive blasting using pneumatic blasting device. Blasting parameter used: air pressure $0.4 \mathrm{MPa}$, distance of a nozzle from the base material $300 \mathrm{~mm}$, impact angle of the abrasive $75^{\circ}$. Abrasive used: white corundum F 22, particle size $0.56 \mathrm{~mm}$.

The thickness of the coatings was determined microscopically on perpendicular metallographic crosssections. In order to simulate the operating conditions, the coatings were subjected to thermal cyclic loading in an electric chamber furnace SM Linu Elektro Therm $\mathrm{GmbH}$. One thermal cycle consisted of heating the samples to $600{ }^{\circ} \mathrm{C}$ for 10 minutes and then cooling in still air to room temperature. The test samples were collected after 5 and 10 thermal cycles.

The adhesion of the coatings was determined by a pull-off test (STN EN 582) - a perpendicular pull-off the joint between the coating and the metal counterpart formed by the high strength adhesive.

Microhardness of the evaluated coatings was measured in accordance with STN EN ISO 4516 (STN 038159) by Vickers hardness test on micro hardness tester HMV-2, SHIMADZU. Measurements were performed on transverse metallographic cross-sections. The test load was $980.7 \mathrm{mN}$ (100 g, HV 0.1) and the dwell time was 15 seconds.

Measurement of corrosion resistance of coatings was done by Potentiodynamic Polarization. Samples were exposed to $3.5 \% \mathrm{NaCl}$ solution. Tests were performed on the Potenciostat SP 150, Bio-Logic Science Instruments, and processed using the EC-Lab V10 software. There was used 3-electrode circuit connection (Fig. 1): reference electrode - saturated calomel electrode $(\mathrm{SCE})$, counter electrode - platinum electrode $(\mathrm{Pt})$, working electrode - investigated coating.

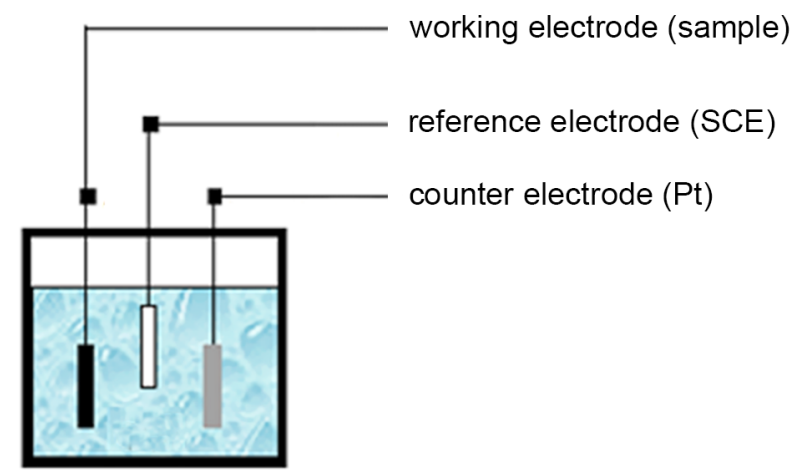

a)

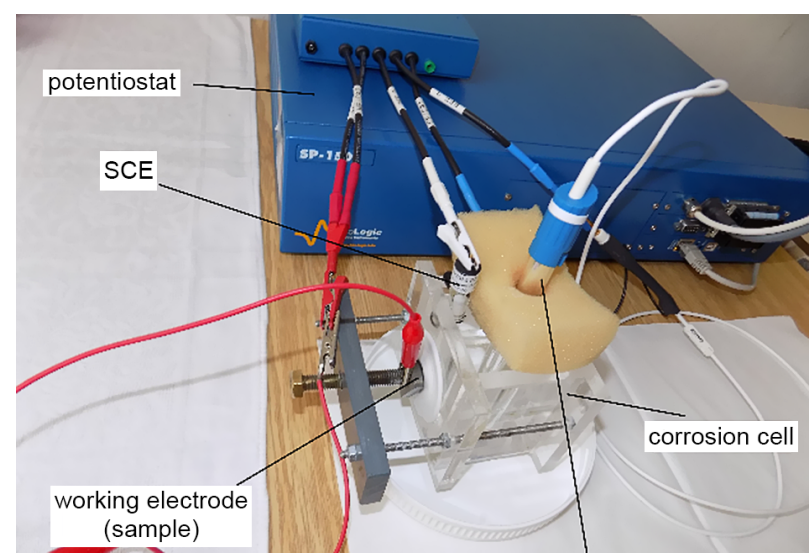

a)

Fig. 1. Connection for corrosion measurement by linear polarization

The start of the measurement consisted of stabilizing the electrode potential Er [V] within 30 minutes. The software recorded values every 5 seconds or $5 \mathrm{mV}$. The polarization ranged from $-0.25 \mathrm{mV}$ against the free potential, up to $0.25 \mathrm{mV}$ against the saturated calomel electrode at a polarization rate of $1 \mathrm{mV} \mathrm{s}^{-1}$. The resulting current densities, depending on the inserted potential, were plotted in semilogarithmic coordinates and analysed by Tafel analysis.

A diffraction X-ray phase analysis was performed to detect the change in the phase composition of the coatings during thermal cyclic loading. Diffraction experiments were recorded on a Philips X'Pert PRO device using $\mathrm{X}$-ray bulb with $\mathrm{Cu}$ anode in Bragg-Brentano geometry. To remove the $\mathrm{CuK} \beta$ component of the primary beam radiation, a $\mathrm{Ni}$ filter was used and $\mathrm{CuK} \alpha 2$ radiation was removed from the recording using the Rachinger method. The diffraction pattern was recorded 
by the X'Celerator rapid detector under following experimental conditions: measurement range $2 \theta 28^{\circ}-100^{\circ}$, increment $0.033^{\circ}$, recording time 15 seconds. The detected phases were identified with help of PDF2 database.

\section{RESULTS}

Based on methodology described above, the selected properties of the coatings were determined depending on the number of thermal cycles. The metallographic cross-sections and the average coating thickness are shown in Fig. 2.

Hardness of the coatings are shown in Fig. 3. The coating hardness ranged from 1050 to $1325 \mathrm{HV} 0.1$. Higher hardness was found on the WC-WB-Co coating, which is due to the higher content of hard particles (WC and $\mathrm{WB}$ ) in the matrix compared to the $\mathrm{WC}-\mathrm{FeCrAl}$ coating. Due to thermal cycles, the microhardness did not change significantly. Fig. 4 shows the force needed for disruption the test joint to determine the adhesion of the coatings.



a) WC-FeCrAl $(164 \mu \mathrm{m})$

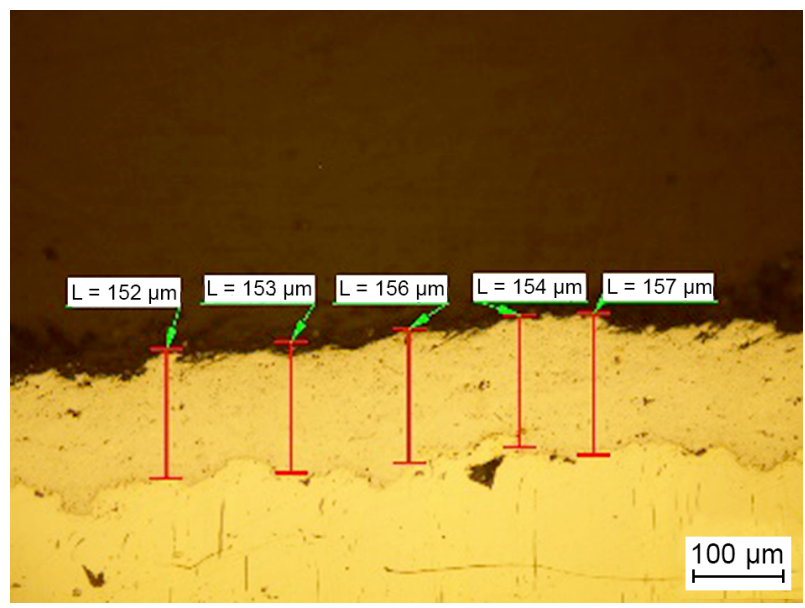

b) WC-WB-Co $(155 \mu \mathrm{m})$

Fig. 2. Metalographic cross-sections and thickness of coatings

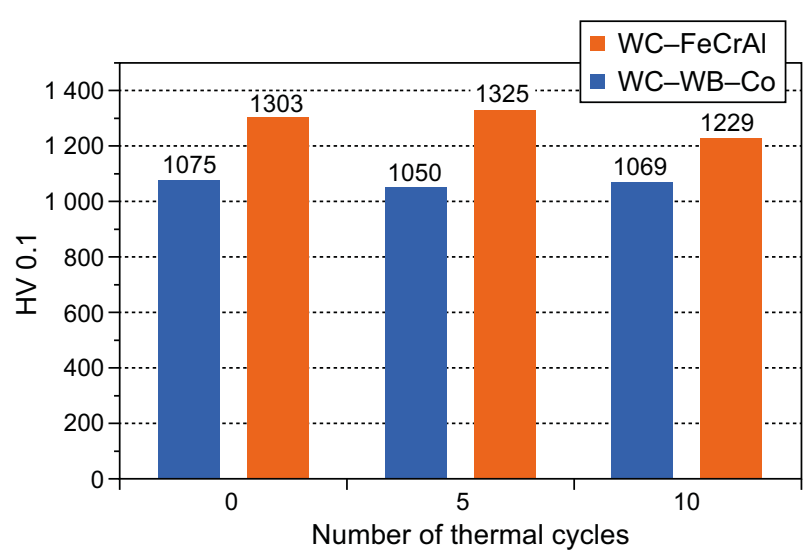

Fig. 3. Microhardness of coatings as-sprayed and after thermal cycles

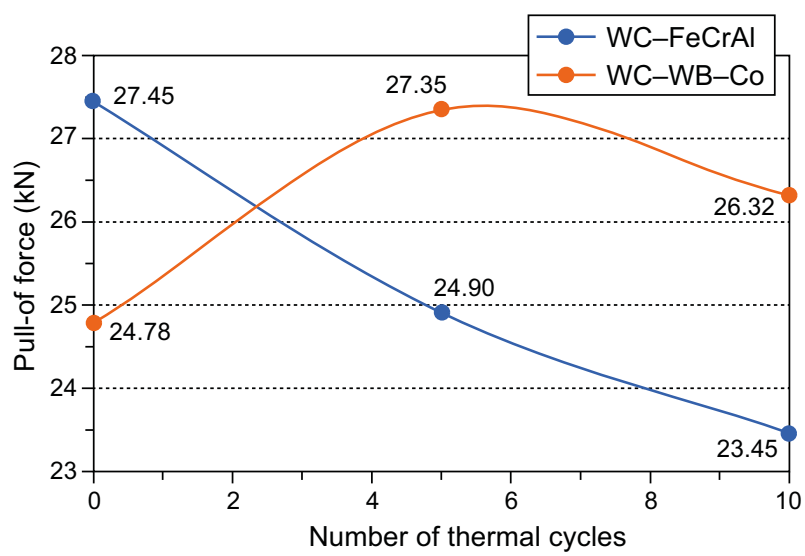

Fig. 4. Pull-off adhesion test

The force needed for disruption the test joint ranged from $23.45 \mathrm{kN}$ to $27.45 \mathrm{kN}$ (which represents the stress of 48-56 MPa), but the breakage occurred at the interface of the adhesive and the coating. This means, that the coating cohesion and adhesion is thus higher than the separation tension.

In Fig. 5 and 6 can be seen the typical fracture appearance of the WC-based coatings. No carbide par-ticles are visible, which indicates good adhesion at the interface between soft binding matrix and WC (or WC and WB) particles, matrix perfectly envelops hard carbide particles. The appearance of fracture surfaces did not change with thermal cyclic loading.

The polarization curves of both coatings, depending on the number of thermal cycles, are shown in Figures 7 and 8 .

Measurements of corrosion properties have confirmed that due to thermal cyclic loading, corrosion potential values have shifted towards more positive values. In Table 2 are listed the corrosion characteristics of the evaluated coatings depending on the thermal cyclic load. 


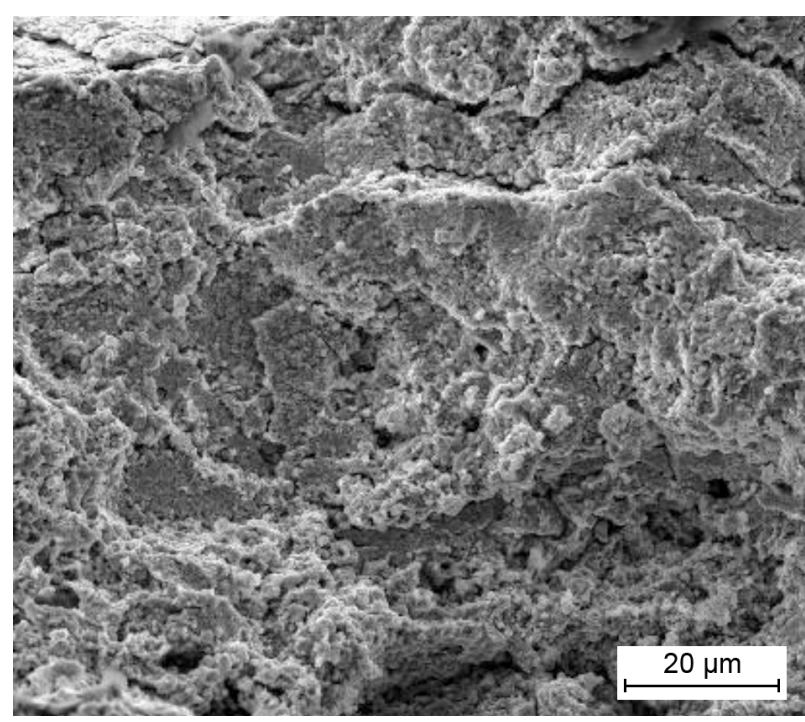

a) as-sprayed



b) 5 thermal cycles

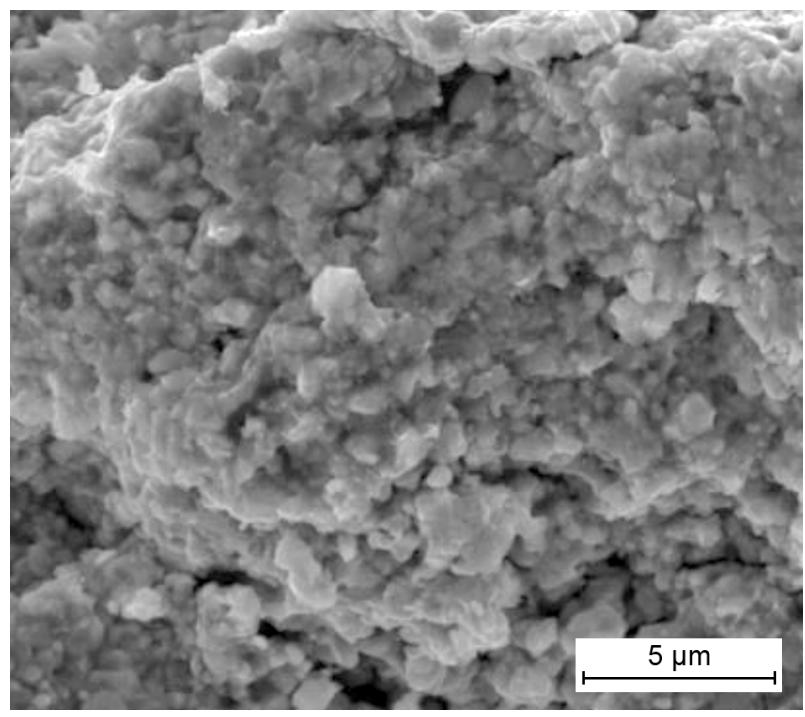

c) 10 thermal cycles

Fig. 5. Fracture surfaces of WC-FeCrAl coating

Koroze a ochrana materiálu 63(4) 167-173 (2019)

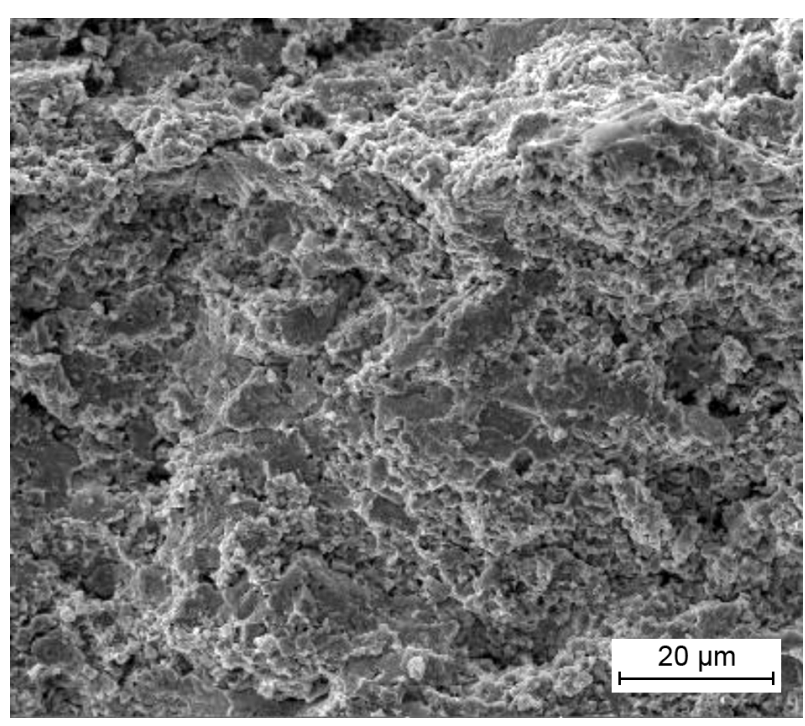

a) as-sprayed

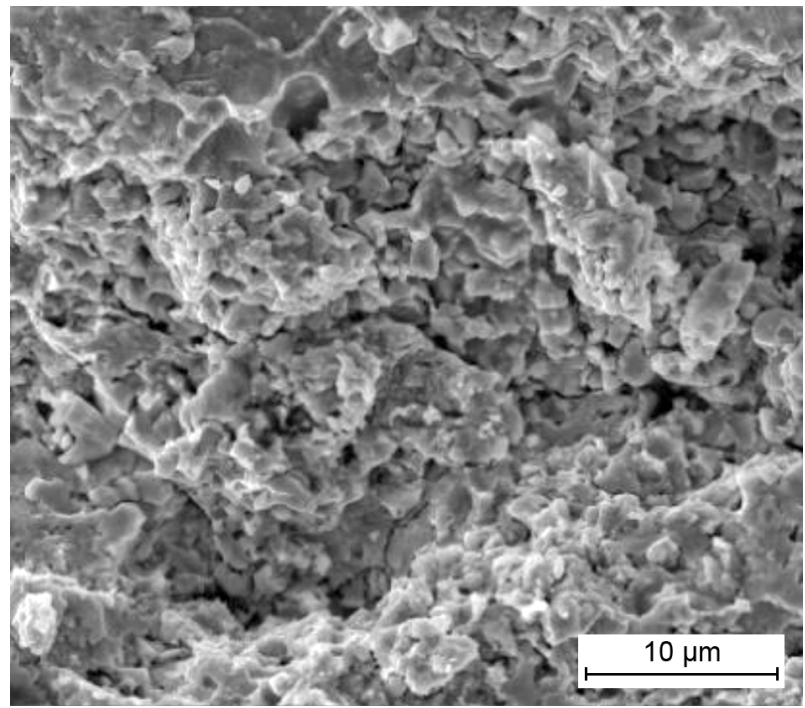

b) 5 thermal cycles

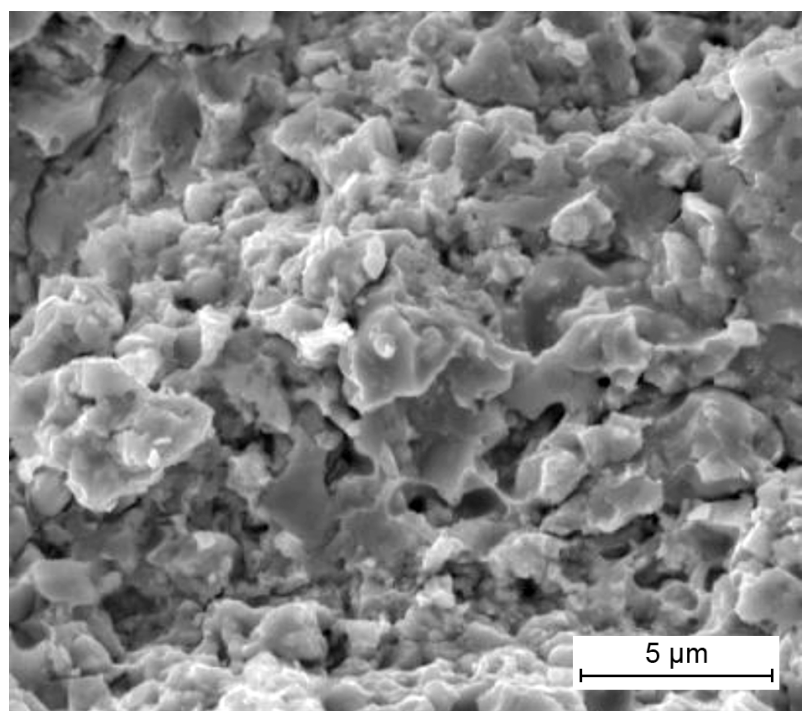

c) 10 thermal cycles

Fig. 6. Fracture surfaces of WC-WB-Co coating

DOI: $10.2478 / \mathrm{kom}-2019-0022$ 170 


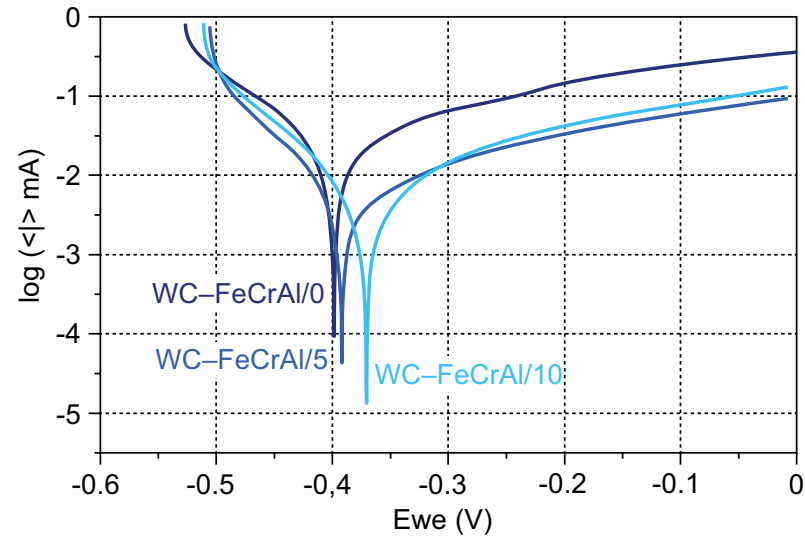

Fig. 7. Potentiodynamic polarization curves of WC-FeCrAl coating



Fig. 8. Potentiodynamic polarization curves of WC-WB-Co coating

In ref. [3] authors have found similar corrosion characteristics of coatings applied by HVOF and HVAF technology. The higher hardness of WC-WB-Co coating, according [3], might have a positive effect on its corrosion behavior after deposition (as-sprayed).

Fig. 9 shows the diffraction curves of the coatings in dependence on thermal load.

In $\mathrm{WC}-\mathrm{FeCrAl}$ coating (as-sprayed) were identified $\mathrm{WC}$ and $\mathrm{W}_{2} \mathrm{C}$ phases. After the 5 and 10 heat cycles no changes in phase composition or phase ratios were observed for this coating.
In $\mathrm{WC}-\mathrm{WB}-\mathrm{Co}$ coating (as-sprayed), $\mathrm{WC}, \mathrm{W}_{2} \mathrm{C}$, $\mathrm{WB}_{2}$, Co phases were identified and the $\mathrm{W}_{2} \mathrm{CoB}_{2}$-related phase can be also observed in the diffraction pattern. Since the layer is not formed under equilibrium conditions, the $\mathrm{W}_{2} \mathrm{CoB}_{2}$ phase can occur in the metastable, or non-stoichiometric state. Therefore, its reflections are slightly shifted in the measured reciprocal space $2 \theta$. In the coating after thermal cyclic loading, the $\mathrm{CoWO}_{4}$ and $\mathrm{WO}_{3}$ oxide phases were also observed. Surface passivation occurred. Oxide phases increase with the number of thermal cycles, which is manifested by increasing in intensity of peaks corresponding to oxides and the relative decreasing in the reflection intensity of the WC phase relative to the reflections of the oxides. It is also possible to observe faster growing of the oxidation phase $\mathrm{CoWO}_{4}$ with the increasing number of thermal cycles. Similar results of phase analysis was found in [3].

Phase analysis performed after the thermal cycles were identified new oxide phases in the WC-WB-Co coating, which resulted in a more pronounced change in corrosion potential over the thermal cyclic loading of the WC-WB-Co coating compared to the WC-FeCrAl.

\section{CONCLUSION}

The paper presents the results of experimental work aimed on the possibility of replacing coatings containing carcinogenic elements such as cobalt and nickel with new types of so-called "green carbides" with an environmentally friendly matrix. The WC-FeCrAl coating, which was considered as a possible substitute, did not lag behind WC-WB-Co in any aspect - it showed high adhesion, high hardness, and improved thermal stability and oxidation resistance compared to WC-WB-Co at temperatures around $600{ }^{\circ} \mathrm{C}$. There was no formation of oxide phases or other phases indicating decomposition of the coating during repeated thermal exploitation. Similarly, the corrosion properties during thermal loading showed less change than in the WC-WB-Co coating. Experimental works have confirmed that $\mathrm{WC}-\mathrm{FeCrAl}$ coating ( $\mathrm{Ni}$ and $\mathrm{Co}$ free) is a suitable substitute for commercially used composite coatings under conditions used in experimental work.

Tab. 2. Scratch test - critical force $\mathrm{Fc}$ at coating failure

\begin{tabular}{|l|c|c|c|c|c|c|}
\hline coating & \multicolumn{3}{|c|}{ WC-FeCrAl } & \multicolumn{3}{c|}{ WC-WB-Co } \\
\hline thermal cycles & 0 (as-sprayed) & $\mathbf{5}$ & $\mathbf{1 0}$ & $\mathbf{0}$ (as-sprayed) & $\mathbf{5}$ & $\mathbf{1 0}$ \\
\hline $\mathrm{E}_{\text {corr }}(\mathrm{mV} / \mathrm{SCE})$ & -399 & -391 & -372 & -565 & -523 & -478 \\
\hline $\mathrm{i}_{\text {corr }}(\mu \mathrm{A})$ & 21 & 4 & 3 & 19 & 27 & 12 \\
\hline$\beta \mathrm{c}(\mathrm{mV})$ & 99 & 54 & 62 & 238 & 140 & 121 \\
\hline$\beta \mathrm{a}(\mathrm{mV})$ & 203 & 192 & 115 & 469 & 337 & 252 \\
\hline $\mathrm{r}_{\text {corr }}\left(\mathrm{mm} \mathrm{a}^{-1}\right)$ & 1.4 & 0.3 & 0.8 & 1.2 & 1.7 & 0.8 \\
\hline
\end{tabular}




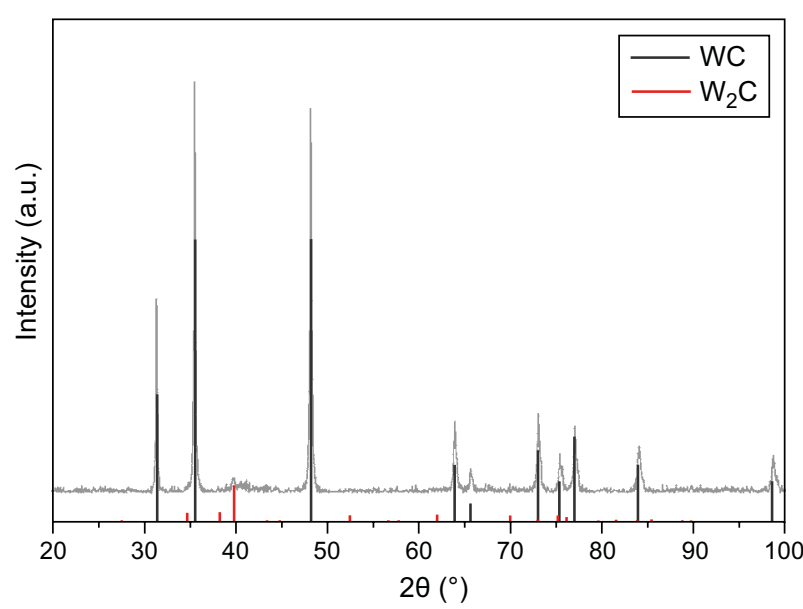

a) as-sprayed

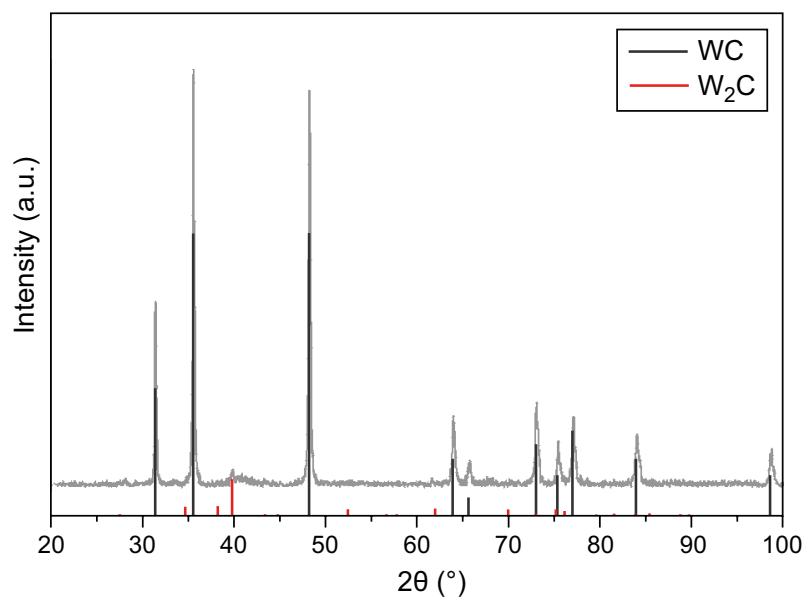

c) after 5 thermal cycles



e) after 10 thermal cycles

Fig. 9. X-ray diffraction analysis of coatings

\section{Acknowledgements}

This work was supported by the Ministry of Education, Science, Research and Sport of the Slovak Republic (VEGA 1/0424/17) and Slovak Research and Development Agency (APVV-16-0359).

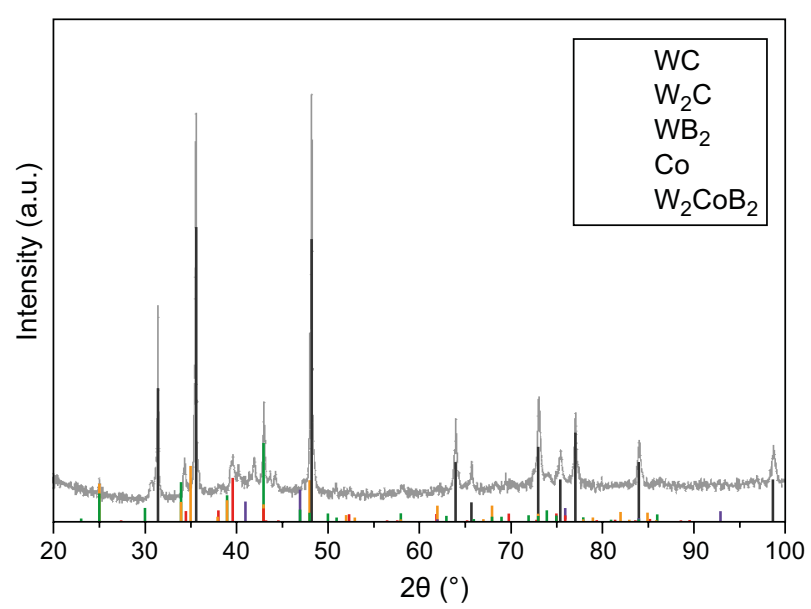

b) as-sprayed



d) after 5 thermal cycles

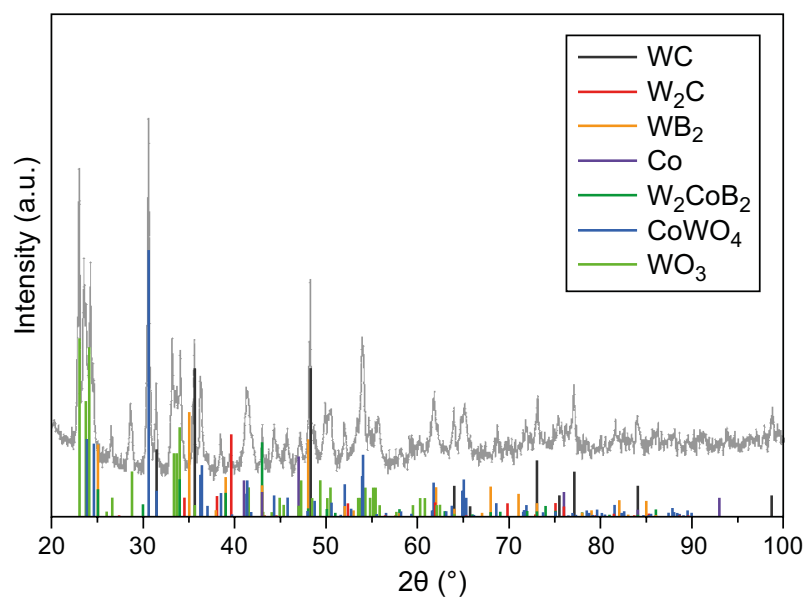

f) after 10 thermal cycles

\section{REFERENCES}

1. Brezinová J., Landová M., Guzanová A., Dulebová L'., Draganovská D.: Microstructure, Wear Behavior and Corrosion Resistance of WC-FeCrAl and WC-WB-Co Coatings. Metals 2018, 8(6), 399. 
2. Bolelli G., Hulka I., Koivuluoto H., Lusvarghi L., Milanti A.: Properties of WC-FeCrAl coatings manufactured by different high velocity thermal spray processes. Surf. Coat. Technol. 2014, 247, 74-89.

3. Hulka I., Utu D., Serban V.-A., Dan M.-L., Matikainen V., Vuoristo P.: Corrosion Behavior of WC-FeCrAl Coatings Deposited by HVOF and HVAF Thermal Spraying Methods. Chem. Bull. Politeh. Univ. Timis. Ser. Chem. Environ. Eng. 2016, 61, 1-6.

4. Nahvi S.M., Jafari M.: Microstructural and mechanical properties of advanced HVOF-sprayed WC-based cermet coatings. Surf. Coat. Technol. 2016, 286, 95-102.

5. Milanti A., Koivuluoto H., Vuoristo P., Bolelli G., Bozza F., Lusvarghi L.: Microstructural Characteristics and Tribo- logical Behavior of HVOF-Sprayed Novel Fe-Based Alloy Coatings. Coatings 2014, 4, 98-120.

6. Bolelli G., Börner T., Bozza F., Cannillo V., Cirillo G., Lusvarghi L.: Cermet coatings with Fe-based matrix as alternative to WC-CoCr: Mechanical and tribological behaviours. Surf. Coat. Technol. 2012, 206, 4079-4094.

7. Brezinová J., Guzanová A., Draganovská D., Bronček J.: Quality Evaluation of HVOF Coatings on the Basis of WC-Co in Tribocorrosive Conditions. Mater. Sci. Forum 2015, 811, 63-66.

8. Brezinová J., Guzanová A., Draganovská D., Maruschak P., Landová M.: Study of selected properties of thermally sprayed coatings containing WC and WB hard particles. Acta Mech. Autom. 2016, 10, 296-299. 